\title{
Attitudes of medical students in Lahore, Pakistan towards the doctor-patient relationship
}

Waqas Ahmad, Edward Krupat, Yumna Asmaa, Noor-E- Fatima, Rayan Attique, Umar Mahmood, Ahmed Waqas

Background. A good doctor-patient relationship is the centre-stone of modern medicine. Patients are getting increasingly aware about exercising their autonomy and thus modern medicine cannot deliver all its advances to the patients if a good doctor-patient relationship is not established. We initiated this study with the aim to assess the leaning of medical students, who are the future physicians, towards either a doctor-centered or a patient-centered care and explore the effects of personal attributes on it like gender, academic year etc. Materials \& Methods. A cross-sectional study was conducted between July-Sep 2013. CMH Lahore Medical and Dental College Ethical Review Committee approved the study questionnaire. The study population consisted of 1181 medical students in years 1-5 from two medical colleges. English version of Patient Practitioner Orientation Scale (PPOS) was used to assess attitudes of medical students towards doctorpatient relationship. PPOS yields a mean score range of 1-6 where 1 signifies tendency towards a doctor centered relationship and 6 signifies patient centered relationship. The relationship between PPOS scores and individual characteristics like gender, academic year etc. were examined by multiple regression. Results. A total of 783 students formed the final sample (response rate $=92 \%$ ). Mean PPOS score of the entire sample was 3.40 ( \pm .49 S.D). Mean sharing sub-scale score was 3.18 ( \pm 0.62 S.D. Mean caring sub-scale score was 3.63 ( \pm 0.56 S.D). Characteristics associated with most patient-centered attitudes were advanced academic year, having a clinical rotation, foreign background and studying in a private college. Gender, having doctor parents, relationship and residence status had no bearing on the attitudes ( $p>0.05$ ). Conclusion. Despite ongoing debate and emphasis on a patient-centered curriculum, our study suggests that current curriculum and its teachings are not producing the results they are designed to achieve. Students should be adequately exposed to the patients from the beginning of their medical education in clinical settings which are more sympathetic to a patient-centered care. 
"Attitudes of Medical Students in Lahore, Pakistan towards the Doctor-Patient

5 Authors: Waqas Ahmad ${ }^{1 *}$, Edward Krupat $^{2}$, Yumna Asma ${ }^{1}$, Noor-E-Fatima ${ }^{1}$, Rayan Attique ${ }^{1}$,

6 Umar Mahmood $^{1}$, Ahmed Waqas ${ }^{1}$.

7

${ }^{1} \mathrm{CMH}$ Lahore Medical College and Institute of Dentistry, Shami Road, Lahore Cantt, Pakistan.

$9{ }^{2}$ Center for Evaluation, Harvard Medical School, 384 MEC, 260 Longwood Avenue, Boston,

10 Massachusetts, United States of America.

11

12

*Corresponding Author

13

E-mail: waqas_lalamusa@yahoo.com (WA)

14

15

16

17 


\section{Abstract:}

Background. A good doctor-patient relationship is the center stone of modern medicine.

Patients are getting increasingly aware about exercising their autonomy and thus modern medicine cannot deliver all its advances to the patients if a good doctor-patient relationship is not established. We initiated this study with the aim to assess the leaning of medical students, who are the future physicians, towards either a doctor-centered or a patient-centered care and explore the effects of personal attributes on it like gender, academic year etc.

Materials \& Methods. A cross-sectional study was conducted between July-Sep 2013. CMH

Lahore Medical and Dental College Ethical Review Committee approved the study questionnaire. The study population consisted of 1181 medical students in years 1-5 from two medical colleges. English version of Patient Practitioner Orientation Scale (PPOS) was used to assess attitudes of medical students towards doctor-patient relationship. PPOS yields a mean score range of 1-6 where 1 signifies tendency towards a doctor centered relationship and 6 signifies patient centered relationship. The relationship between PPOS scores and individual characteristics like gender, academic year etc. were examined by multiple regression.

Results. A total of 783 students formed the final sample (response rate=92\%). Mean PPOS score of the entire sample was 3.40 ( \pm .49 S.D). Mean sharing sub-scale score was $3.18( \pm 0.62$ S.D. Mean caring sub-scale score was 3.63 ( \pm 0.56 S.D). Characteristics associated with most patientcentered attitudes were advanced academic year, having a clinical rotation, foreign background and studying in a private college. Gender, having doctor parents, relationship and residence status had no bearing on the attitudes $(\mathrm{p}>0.05)$. 
47 Conclusion. Despite ongoing debate and emphasis on a patient-centered curriculum, our study

48 suggests that current curriculum and its teachings are not producing the results they are designed

to achieve. Students should be adequately exposed to the patients from the beginning of their medical education in clinical settings which are more sympathetic to a patient-centered care.

\section{Introduction:}

A good doctor-patient relationship is the center-stone of modern medicine. The stronger the relationship, the better are the patient's compliance to the treatment (Choi, Kim \& Park, 2004), disease outcomes and satisfaction (Heisler et al., 2005; Mallinger, Griggs \& Shields, 2005). Just like a weak link in a chain, the doctor-patient relationship is under most strain when kept vertical (doctor-centered or paternalistic) which doesn't allow the patient any control over the flow of information or treatment. On the other hand when it is kept horizontal (patient-centered or egalitarian) the patient is encouraged to play the role of a partner (Campbell \& McGauley, 2005) and takes greater responsibility for his own health (Kaba \& Sooriakumaran, 2007). It benefits doctors by decreasing the incidence of complaints and litigation (Fallowfield, 2008) and enables them to work at an optimum level to attain the four prima facie maxims (beneficence, nonmaleficence, respect for autonomy and justice) (Tor, 2001) of modern medicine.

Patients in the modern era are becoming more and more autonomous (Shankar \& Piryani, 2009), an entity seldom considered in the past but modern medicine cannot advance without incorporating this essential ethical necessity (Tor, 2001). Patients question the doctors' decisions and expect satisfactory answers. This emphasizes the importance of good communication skills necessary to build good doctor patient relationship. Studies have shown that good communication skills can be achieved by structured training, which runs contrary to past beliefs 
that good communication is an intrinsic quality of a doctor and cannot be taught (Smith et al., 2000).

2

It is very logical to assess the attitudes of future physicians towards doctor-patient relationship which is the very foundation of modern medicine. A growing body of research has demonstrated that medical students around the globe show wide difference in their attitudes towards the doctor-patient relationship. Researchers have used a valid and reliable scale called the Patient Practitioner Orientation Scale (PPOS) (Haidet et al., 2002) to measure this attitude in countries like Nepal (Shankar et al., 2006), Korea (Choi, Kim \& Park, 2004) and Greece (Tsimtsiou et al., 2005). Medical students in Brazil have highly positive beliefs about patient centered care (PPOS score of $4.66 \pm 0.44$ S.D) (Ribeiro, Krupat \& Amaral, 2007), followed closely by American medical students (PPOS score is $4.57 \pm 0.48$ S.D) (Haidet et al., 2002).

As indicated by a study in Nepal (PPOS score of $3.71 \pm 0.48$ S.D), medical students in Asia have a tendency towards Doctor Centered care (Haidet et al., 2002; Shankar et al., 2006), which is associated with decreased patient satisfaction (Krupat et al., 2000) in many of the countries this relationship has been studied.

Paucity of knowledge on dynamics of doctor-patient relationship in Pakistani medical schools warranted this study which has been designed with two aims: 1) to assess the leaning of Pakistani medical students towards either a doctor or patient centered care 2) to analyze associations of demographic characterstics, year of study and student-patient interaction with patient centered care as assessed with PPOS.

1 Materials \& Methods:

2 Study Sample: 
Descriptive, cross-sectional study design and convenience (non-probability) sampling technique was employed. In Pakistan undergraduate medical education lasts 5 years. This includes 2 preclinical years and 3 clinical years. Students from 1 st and 2 nd academic year (pre-clinical years) do not have a clinical rotation in their curriculum. The dominant form of teaching in the medical colleges across the country is conventional consisting of didactic lecture techniques, nonproblem-based learning (PBL) teaching methods, long lectures, tutorials and practical tasks (Waqas et al., 2015). The attitudes of medical students of academic year 1 to 5 from two medical colleges, a Government College (Allama Iqbal Medical College) and a Private College (CMH Lahore Medical College), were assessed towards doctor-patient relationship between July 2013 and Sep 2013. A standardized questionnaire with English version of PPOS and a series of demographic questions was used. Forms were distributed to 1274 students (858 in govt. and 416 in private) out of which 1181 responded [collective response rate $92 \%$ (91\% and $94.2 \%$ respectively)]. Total number of students in Allama Iqbal Medical College, Lahore is 1,650 and 650 in CMH Lahore Medical College.

\section{Instrument:}

The doctor-patient relationship was assessed by using a reliable instrument called Patient Practitioner Orientation Scale (PPOS) (Haidet et al., 2002). The PPOS contains 18-items and uses a Likert-scale format and measures the respondent's leaning towards a doctor-centered or a patient-centered belief. Each item has 6 possible responses ranging from 1 (strongly agree) to 6 (strongly disagree). The scale has two subscales which measure two domains of doctor-patient relationship: Sharing and Caring. Sharing refers to an individual's belief that a patient should share the power, control and flow of information equally with their doctor. Caring refers to an individual's belief that a patient should be treated as a whole and treated with good emotional 
116 rapport rather than as a condition or disease. Both sub-scales have 9 items each. PPOS yields a

117 mean score range of 1-6 where 1 signifies tendency towards a doctor centered relationship and 6

118 signifies patient centered relationship.

\section{Statistical Analysis:}

120 SPSS Inc., (Chicago, Illinois, USA) version 21 software was used for analysis. Descriptive

121 statistics and frequencies were calculated for subscale scores on PPOS and demographic 122 variables respectively. Multiple regression analysis (backward method) was run to predict PPOS 123 scores, sharing and caring subscale scores from gender, age, study year, rotation (Outpatient 124 department, inpatient department and not applicable) and nationality (Pakistani/overseas). 125 Students having different residence (off campus/in campus) and relationship status were 126 hypothesized to have different attitudes towards doctor-patient relationship because of their 127 exposure to different psycho-social stressors and hence included in the regression analysis. The 128 assumptions of linearity, independence of errors, homoscedasticity, unusual points and normality 129 of residuals were assessed.

130 Ethics Statement:

131 CMH Lahore Medical and Dental College Ethical Review Committee approved the study 132 questionnaire. Permission was also granted for data collection by Dean of Allama Iqbal Medical 133 College, Lahore.

134 Results:

135 Students from academic year 1-5 of both colleges participated in this research $(\mathrm{N}=1181)$. Out of 1361181,398 forms were discarded due to incomplete demographics and more than 3 missing 137 responses in PPOS (final sample $\mathrm{N}=783$ ). There were $226(28.9 \%)$ males and 557 (71.1\%)

138 female students. The sample distribution by gender, college, academic year etc. is shown in 
139 Table-1. The mean PPOS score of the entire sample was 3.40 ( \pm 0.49 S.D). Mean sharing sub-

140 scale score was 3.18 ( \pm 0.62 S.D). Mean caring sub-scale score was 3.63 ( \pm 0.56 S.D). Multiple

141 regression analysis yielded significant models for mean PPOS scores, sharing and caring scores

142 (Table 2). Mean PPOS scores were positively associated with students from privately financed

143 medical college and foreign background. Students rotating in inpatient or outpatient departments

144 (OPDs) scored significantly higher on PPOS scale than those who were not rotating in a clinical

145 setting at present. Similar trends were observed in sharing and caring domains. Students having a

146 foreign background, currently in a higher academic year and studying in a privately financed

147 medical college were associated with higher scores on sharing sub-scale. Scores on caring sub-

148 scale were positively associated with foreign background and rotation in outpatient (OPDs) and

149 inpatient departments. Having doctor parents, residence and relationship status had no bearing on

150 doctor-patient relationship $(\mathrm{p}>0.05)$. 


\section{Discussion:}

154 Our findings suggest that Pakistani medical students very much believe in "Doctor Knows Best" 155 (Tor, 2001). They scored even lower than their Nepali counterparts (Shankar et al., 2006), except 156 in caring domain, making them the most doctor-centered of those samples of medical students in several studies done around the world. Female gender, which is traditionally associated with patient-centered care and is shown to have leaning towards it (Haidet et al., 2002), had statistically the same distribution of PPOS scores as males of this sample $(\mathrm{p}>0.05)$. This finding although contradictory to the studies conducted in America and Brazil is consistent with findings in Nepal (another Asian country) (Haidet et al., 2002; Shankar et al., 2006; Ribeiro, Krupat \& Amaral, 2007). This consistency might be due to social, religious and cultural differences present in the two continents i.e. Americas and Asia.

164 Relationship status had no significant association with mean PPOS scores. Our sample had a very small proportion of students who were involved in a premarital relationship as having premarital relationships in this part of the world are discouraged based on religious and cultural norms. No clear pattern was established in consecutive academic years in terms of mean PPOS scores or caring sub-scale scores. However sharing domain scores showed a clear positive association with higher academic years which suggests that students, as they go into higher academic years, become more aware about the rights of the patients and are willing to share the power of treatment choices with them. This finding is similar to the study done in Brazil

172 (Ribeiro, Krupat \& Amaral, 2007) but contradictory to the ones done in USA where good patient-centred care is associated with early academic years (Haidet et al., 2002). Attributes associated with leaning towards patient-centred care were: studying in a privately financed medical college, having a foreign background and rotating in outpatient or inpatient departments 
as opposed to those who were not currently rotating in a clinical setting. These attributes were consistent throughout the mean PPOS scores and sharing sub-scale. Privately financed medical colleges have a better teacher to student ratio with a lesser patient load in attached private hospitals as opposed to government financed colleges. This might explain the higher scoring of students of private medical school. Another interesting finding in our study was that students who had a clinical rotation (students in clinical years), either in outpatient or inpatient departments, scored better than those who did not have a rotation (students in pre-clinical years). These finding clearly divide our sample into the ones who just see patient on pages of books while the others who interact with them and see them as a whole. It also illustrates the importance of patient interactions and necessitates the student-patient interaction to begin at an early stage of medical training. Students who rotated in an inpatient setting showed a stronger positive association with mean scores on PPOS than those who rotated in an outpatient setting which could be due to a continuous flow of patients in outpatient setting who get a very brief interaction with doctor/students as opposed to patients in wards who stay there for long durations and offer a better chance for students to get to know them and see them as a whole rather than a disease. Better performance by foreign students might be due to not sharing the Asian culture which is associated with doctor-centered care (Haidet et al., 2002).

Medical students join this profession of medicine to heal patients (Lloyd-Williams \& Dogra, 2004) but instead are taught to heal the disease only. The present system of medical education does not necessitate the development of characteristics like good communication skills etc. which are necessary for a good patient-centered care. The pressures they are exposed to (academic, psycho-social and health related) further retard their shaping into a patient-centered practitioner (Waqas et al., 2015). 
199 However, this does not mean that medical students cannot develop these skills after leaving

200 medical school but it is much more beneficial to the patients and healthcare system if they are

201 taught to focus on the patient as a whole sooner than later in their medical career. Another reason

202 for medical students to be more doctor-centered could be due to the teaching style of practicing

203 doctors who teach them while attending to their patients. The environment in which clinicians

204 teach is not always conducive to high ideals of doctor-patient relationship that the students are

205 taught in lecture theatres (Grilo et al., 2014). This opinion is enforced by Humayun A et al. who

206 found that Pakistani doctors did not take informed consent from more than $71 \%$ patients and

207 provided adequate confidentiality to less than $24 \%$ of their patients (Humayun et al., 2008).

208 Informed consent is defined as "patients' autonomy in decisions and right to complete

209 information" and confidentiality entails right of the patient to informational privacy (Humayun et

210 al., 2008). When medical students are taught in such a doctor-centered environment it is natural

211 for them to embody such practices because when a student realizes that doctors, not following

212 the prima facie maxims (Tor, 2001), are still able to have a very healthy practice then he wonders

213 if formalities like consent or confidentiality even matter in the real world medicine. Doctors in

214 the government owned hospital did not take consent from more than $90 \%$ patients and provided

215 adequate confidentiality to less than $11 \%$ of their patients (Humayun et al., 2008). Teachings of

216 such doctors could explain our finding that medical students from government owned medical

217 school scored lower on PPOS than of private medical school $(\mathrm{p}<0.05)$.

218 Shaikh et al. have reported the prevalence of stress to be $90 \%$ in Pakistani medical students

219 (Shaikh et al., 2004). Further studies have shown that psychological stress can cause poor

220 attitudes towards the chronically ill, decreased empathy and high levels of cynicism (Crandall,

221 Volk \& Loemker, 1993) which together amounts to a less favorable patient care. Students who 
222 experience these stresses seldom seek help because of the stigma revolving around psychiatric

223 illnesses (Waqas et al., 2014). For this reason, medical educators should make it mandatory to

224 see the prevalence of such psychiatric illnesses/stressors during the course of medical education

225 and should take prompt actions to protect students from their harmful effects.

226 Conclusion

227 If medical schools want to develop physicians who treat the patient as a whole then medical

228 educators would have to initiate new programs to develop essential characteristics (like good communication skills, empathy etc.) necessary to achieve the prima facie maxims of modern

230 medicine. Students should be adequately exposed to patients from the beginning of their graduate

231 program and in clinical settings which are more favorable to a patient-centered care. Continuous

232 monitoring of the students should be done to identify and mend the factors which push them

233 away from a patient-centered caring attitude and patient-centered role models should be sought

234 for students to observe and follow. Most of what is learned during the graduate program is

235 through "Hidden Curriculum" which is a set of influences functioning at the level of 236 organizational structure and culture (Hafferty, 1998). This is mostly true for Pakistan since its

237 biggest medical university (UHS) has, in recent years, introduced Behavioral Sciences as an

238 integral part of the curriculum in 2007 which is yet to produce its effects in medical practice of

239 Pakistan.

240

241 Limitations and suggestions for future research:

242 Despite our efforts to completely explore the attitude of medical students towards doctor-patient

243 relationship we strongly believe that additional factors should be incorporated into further

244 research done in the future in this domain. 
I. Academic staff from the respective colleges and hospitals was not included in this study which could have aided in measuring the extent of the problem.

II. We conducted our study in just one city. Further studies should include a broader sample comprising of medical students from all the four provinces and all religious and ethnic groups to see if these factors have any effect on Patient-Centered Care.

III. The cross-sectional design of this study limits inferences about causality and temporality.

IV. Since PPOS just measures the orientation and not the behavior of medical students towards Patient-Centered care, future researchers should include means to see the behavior of medical students toward this entity.

\section{Acknowledgement:}

Campbell C, McGauley G. 2005. Doctor-patient relationships in chronic illness: insights from forensic psychiatry. BMJ (Clinical research ed.) 330:667-70.

Choi CJ, Kim JM, Park YG. 2004. Patient-centered attitudes and communication skills in medical students after clerkship. Korean Journal of Medical Education 16:169-177.

Crandall SJS, Volk RJ, Loemker V. 1993. Medical students' attitudes toward providing care for the underserved: are we training socially responsible physicians? JAMA 269:2519-2523. 
Fallowfield LJ. 2008. Treatment decision-making in breast cancer: the patient-doctor relationship. Breast cancer research and treatment 112:5-13.

Grilo AM, Santos MC, Rita JS, Gomes AI. 2014. Nurse Education Today Assessment of nursing students and nurses ' orientation towards patient-centeredness. Nurse Educ Today. 34:3539.

Hafferty FW. 1998. Beyond Curriculum Reform: Confronting Medicine's Hidden Curriculum. Academic Medicine 73:403-407.

Haidet P, Dains JE, Paterniti D a, Hechtel L, Chang T, Tseng E, Rogers JC. 2002. Medical student attitudes toward the doctor-patient relationship. Medical education 36:568-74.

Heisler M, Piette JD, Spencer M, Kieffer E, Vijan S. 2005. The relationship between knowledge of recent $\mathrm{HbA} 1 \mathrm{c}$ values and diabetes care understanding and self-management. Diabetes care 28:816-822.

Humayun A, Fatima N, Naqqash S, Hussain S, Rasheed A, Imtiaz H, Imam SZ. 2008. Patients' perception and actual practice of informed consent, privacy and confidentiality in general medical outpatient departments of two tertiary care hospitals of Lahore. BMC medical ethics 9:14.

Kaba R, Sooriakumaran P. 2007. The evolution of the doctor-patient relationship. International Journal of Surgery 5:57-65.

Krupat E, Rosenkranz SL, Yeager CM, Barnard K, Putnam SM, Inui TS. 2000. The practice orientations of physicians and patients: the effect of doctor-patient congruence on satisfaction. Patient education and counseling 39:49-59.

Lloyd-Williams M, Dogra N. 2004. Attitudes of preclinical medical students towards caring for chronically ill and dying patients: does palliative care teaching make a difference? Postgraduate Medical Journal 80:31-34.

Mallinger JB, Griggs JJ, Shields CG. 2005. Patient-centered care and breast cancer survivors' satisfaction with information. Patient education and counseling 57:342-349.

Ribeiro MMF, Krupat E, Amaral CFS. 2007. Brazilian medical students' attitudes towards patient-centered care. Medical teacher 29:e204-8.

Shaikh BT, Kahloon A, Kazmi M, Khalid H, Nawaz K, Khan NA. 2004. Students, Stress and Coping Strategies: A Case of Pakistani Medical School. Education for Health 17:346-353.

Shankar PR, Dubey a K, Subish P, Deshpande VY. 2006. Attitudes of first-year medical students towards the doctor patient relationship. JNMA; journal of the Nepal Medical Association 45:196-203. 
302

Shankar PR, Piryani RM. 2009. Medical education and medical educators in South Asia--a set of challenges. Journal of the College of Physicians and Surgeons--Pakistan : JCPSP 19:52-6.

Smith RC, Marshall-Dorsey a a, Osborn GG, Shebroe V, Lyles JS, Stoffelmayr BE, Van Egeren LF, Mettler J, Maduschke K, Stanley JM, Gardiner JC. 2000. Evidence-based guidelines for teaching patient-centered interviewing. Patient education and counseling 39:27-36.

Tor PC. 2001. New Challenges Facing the Doctor-Patient. Singapore Medical Journal 42:572575.

Tsimtsiou Z, Papaharitou S, Kantziou M, Hatzichristou D, Krupat E. 2005. Patient-practitioner orientation scale (PPOS): linguistic adaptation in Greek and validation of a scale that measures attitudes towards doctor-patient relationship. Primary Health Care 17:190-197.

Waqas A, Zubair M, Ghulam H, Wajih Ullah M, Zubair Tariq M. 2014. Public stigma associated with mental illnesses in Pakistani university students: a cross sectional survey. PeerJ 2:e698; DOI 10.7717/peerj.698

Waqas A, Khan S, Sharif W, Khalid U, Ali A. 2015. Association of academic stress with sleeping di ffi culties in medical students of a Pakistani medical school : a cross sectional survey. PeerJ 3:e840; DOI 10.7717/peerj.840

\section{Supporting Information}

\section{S1 File. Dataset of the study.}

S2 File. Ethical review committee certificate of approval.

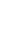


353

354

355

356

357

358

359

360

361

362

363

364

365

Peer] reviewing PDF | (2015:04:4693:3:0:NEW 27 May 2015) 


\section{Table $\mathbf{1}$ (on next page)}

Demographic characteristics of the students. $(N=783)$ 


\begin{tabular}{|c|c|}
\hline College & n (\%) \\
\hline Allama Iqbal Medical College & $509(65 \%)$ \\
\hline CMH Lahore Medical College & $274(35 \%)$ \\
\hline \multicolumn{2}{|l|}{ Gender } \\
\hline Male & $226(28.9 \%)$ \\
\hline Female & $557(71.1 \%)$ \\
\hline \multicolumn{2}{|l|}{ Academic Year } \\
\hline $1^{\text {st }}$ Year & $173(22.1 \%)$ \\
\hline $2^{\text {nd }}$ Year & $145(18.5 \%)$ \\
\hline $3^{\text {rd }}$ Year & $177(22.6 \%)$ \\
\hline $4^{\text {th }}$ Year & $183(23.4 \%)$ \\
\hline $5^{\text {th }}$ Year & $105(13.4 \%)$ \\
\hline \multicolumn{2}{|l|}{ Country of Origin } \\
\hline Pakistan & $750(95.8)$ \\
\hline Foreign & $33(4.2 \%)$ \\
\hline \multicolumn{2}{|l|}{ Doctor Parents } \\
\hline Yes & $197(25.2 \%)$ \\
\hline No & $586(74.8 \%)$ \\
\hline \multicolumn{2}{|l|}{ Residence } \\
\hline On campus & $416(53.1 \%)$ \\
\hline Off campus & $367(46.9 \%)$ \\
\hline \multicolumn{2}{|l|}{ Relationship } \\
\hline Single & $722(92.2 \%)$ \\
\hline Married & $21(2.7 \%)$ \\
\hline Having a boyfriend/girlfriend & $40(5.1 \%)$ \\
\hline \multicolumn{2}{|l|}{ Clinical Rotation } \\
\hline Out Patient Department & $63(8.0 \%)$ \\
\hline Ward & $401(51.2)$ \\
\hline Not Applicable* & $319(40.7)$ \\
\hline
\end{tabular}


*Not Applicable refers to the students from $1^{\text {st }}$ and $2^{\text {nd }}$ academic year who do not have a clinical rotation in their curriculum. 


\section{Table 2 (on next page)}

Multiple regression model for mean PPOS and sub-scale scores. $(N=783)$ 


\begin{tabular}{|c|c|c|c|c|}
\hline Predictors & $\mathrm{B}$ & Std. Error B & Beta & $\mathrm{P}$ value \\
\hline \multicolumn{5}{|c|}{ Mean PPOS scores $\left(\right.$ Adj. $\left.\mathrm{R}^{2}=.063, \mathrm{P}<.001\right)$} \\
\hline Constant & 3.1 & .13 & & $<.001$ \\
\hline CMHLMC vs AIMC & -.13 & .04 & -.12 & $<.001$ \\
\hline Pakistani vs Foreign & .36 & .09 & .15 & $<.001$ \\
\hline $\mathrm{N} / \mathrm{A}$ vs OPD & .26 & .07 & .14 & $<.001$ \\
\hline N/A vs Ward & .12 & .04 & .12 & $<.001$ \\
\hline Residence (On campus/off campus) & .06 & .04 & .06 & $>.05$ \\
\hline \multicolumn{5}{|c|}{ Mean sharing sub-scale scores $\left(\mathrm{Adj} . \mathrm{R}^{2}=.061, \mathrm{P}<.001\right)$} \\
\hline Constant & 2.9 & .15 & & $<.001$ \\
\hline CMHLMC vs AIMC & -.23 & .05 & -.18 & $<.001$ \\
\hline Pakistani vs Foreign & .43 & .12 & .14 & $<.001$ \\
\hline Study Year & .05 & .02 & .12 & $<.001$ \\
\hline \multicolumn{5}{|c|}{ Mean Caring sub-scale scores $\left(\mathrm{Adj} . \mathrm{R}^{2}=.028, \mathrm{P}<.001\right)$} \\
\hline Constant & 3.141 & .125 & & .000 \\
\hline Pakistani vs Foreign & .296 & .099 & .105 & $<.01$ \\
\hline N/A vs OPD & .275 & .077 & .133 & $<.001$ \\
\hline N/A vs Ward & .110 & .042 & .098 & $<.01$ \\
\hline Residence (On campus/off campus) & .072 & .040 & .064 & $>.05$ \\
\hline $\begin{array}{l}* \mathrm{~N} / \mathrm{A}=\text { Student of } 1^{\text {st }} \text { and } 2^{\text {nd }} \text { academ } \\
\text { their curriculum. } \\
\text { OPD= Out Patient Department. } \\
\text { AIMC=Allama Iqbal Medical Colleg } \\
\text { CMHLMC = CMH Lahore Medical C } \\
\text { PPOS = Patient-Practitioner Orientat }\end{array}$ & who do & have any clin & otatio & \\
\hline
\end{tabular}

